Evolution of the Forebrain
\begin{tabular}{|l|l|l|}
\hline Brain Behav Evol 1995;46:224-234 & Laura L. & Bruce \\
\hline L.L. & Timothy J. & Neary \\
\hline T.J.
\end{tabular}

Department of Biomedical Sciences, Creighton University, Omaha, Nebr., USA

\title{
The Limbic System of Tetrapods: A Comparative Analysis of Cortical and Amygdalar Populations Key Words
}

Amygdala

Dorsal ventricular ridge

Cortex

Amphibian

Reptile

Mammal

Evolution

Homology

Abstract

Recent studies of the limbic system of tetrapods have made data available that challenge some of the long-held tenets of forebrain evolution. Using the basic principle of parsimony that the best hypotheses concerning homologies are those requiring the fewest number of evolutionary changes - we have reevaluated comparisons of tetrapod limbic systems. Given the current data, the following points appear to be justified: (1) the common ancestors of reptiles and mammals had a well-developed limbic system in which the basic subdivisions and connections of the amygdalar nuclei were established; (2) the ventral part of the lateral pallium in amphibians appears to be a single structure which corresponds to at least four areas in reptiles: centromedial DVR, ventral anterior amygdala, lateral amygdala, and part of the lateral cortex; (3) the medial pallium in amphibians appears to be homologous with the dorsal and medial cortices in reptiles and with the general and hippocampal cortices in mammals; (4) the cortical targets of the main olfactory bulb in reptiles and mammals appear to be homologous, and their common ancestor probably had a corresponding olfactory pallial field; (5) the targets of the accessory olfactory bulb in amphibians, reptiles, and mammals appear to be homologous, with the exception of nucleus sphericus in reptiles, which lacks an obvious homologue in non-reptiles.

Laura L. Bruce, Department of Biomedical Sciences, Creighton University, Omaha, NE 68178 (USA)

\section{Introduction}

Some twenty-five years ago, many established conceptions concerning vertebrate forebrain evolution began to undergo dramatic changes [e.g., Nauta and Karten, 1970]. Investigations of olfactory and thalamic connections with experimental neuroanatomical techniques revealed that the telecephalon in non-mammalian vertebrates was neither dominated by olfactory input nor lacking significant ascend-

ing sensory input from the dorsal thalamus. Surprisingly, this influx of new data had relatively little effect on the generally held interpretations regarding fields comprising the pallial mantle (cortex), particularly in tetrapods. With few exceptions, e.g. Scalia [1976], the traditional triple field pallium, with 
lateral, dorsal, and medial components that were homologous in amphibians and amniotes, was retained.

The relative stability of opinion regarding the composition and relations of pallial fields contrasts sharply with the

(C) 1995 S. Karger AG. Basel

0006-8977/95/0465-0224

$\$ 8.00 / 0$

\section{Abbreviations}

Agl

agranular insular cortex

AHA

amygdalohippocampal transition area

AL

lateral amygdala (amphibian)

BL

basolateral amygdala

BLC

basolaleral amygdalar complex

$\mathrm{BM}$

basomedial amygdala

CeA

central amygdala

Contra Ctx

contralateral general cortex

$\mathrm{D}$

nucleus of the diagonal band

DC

dorsal cortex

DP

dorsal pallium

DVR

dorsal ventricular ridge

DVRcd

caudodorsal part of dorsal ventricular ridge

DVRcm

cen tromcd $i$ al part of dorsal ventricular ridge

Ent

entorhinal cortex

ExA

external amygdalar nucleus

Gen Ctx

general (non-olfactory, non-hippocampal) cortex

Hp

hippocampus

IA

interstitial amygdala

ic

internal capsule

InfColl

inferior colliculus

Ipsi Ctx

ipsilateral general cortex

LA

lateral amygdala (reptilian)

LAm

lateral amygdala (mammalian)

LC

lateral cortex

lfb

lateral forebrain bundle

$\mathrm{LH}$ 


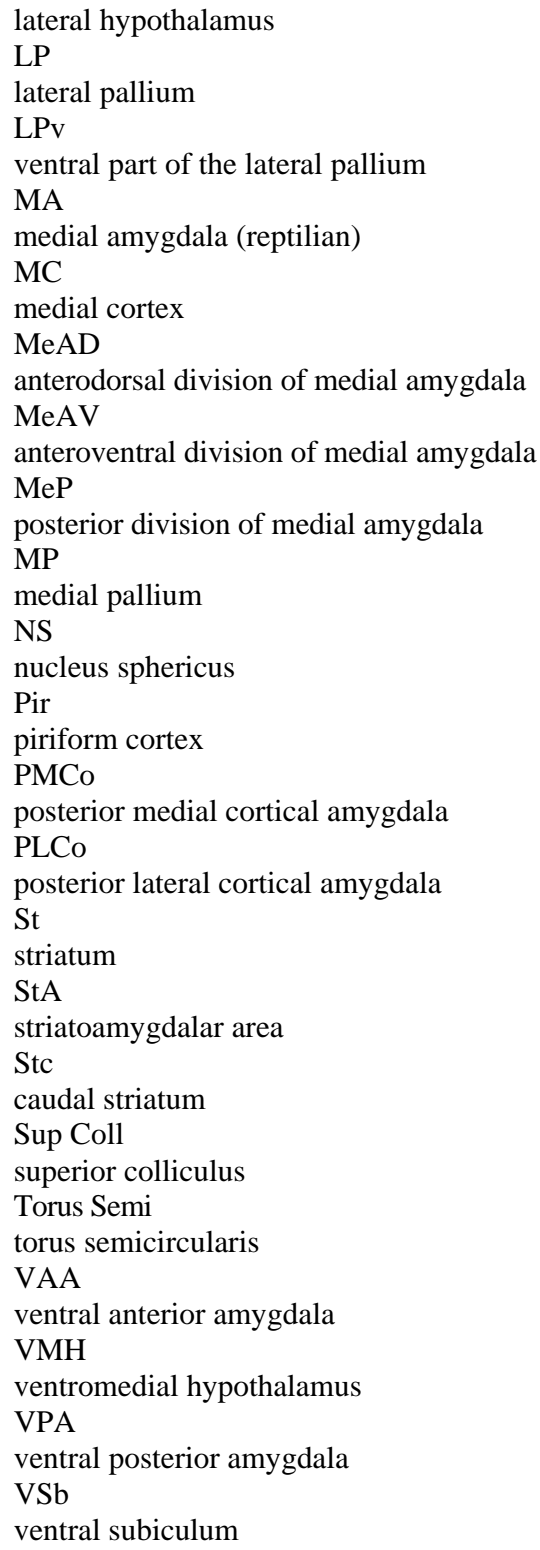

divergence of thought concerning a prominent elevation present in the telencephalon of reptiles and birds, the dorsal ventricular ridge. This structure, in particular its rostral part (rDVR), was previously thought to be related to the striatum in mammals (fig. 1) [Elliot Smith, 1919; Dart, 1920; 


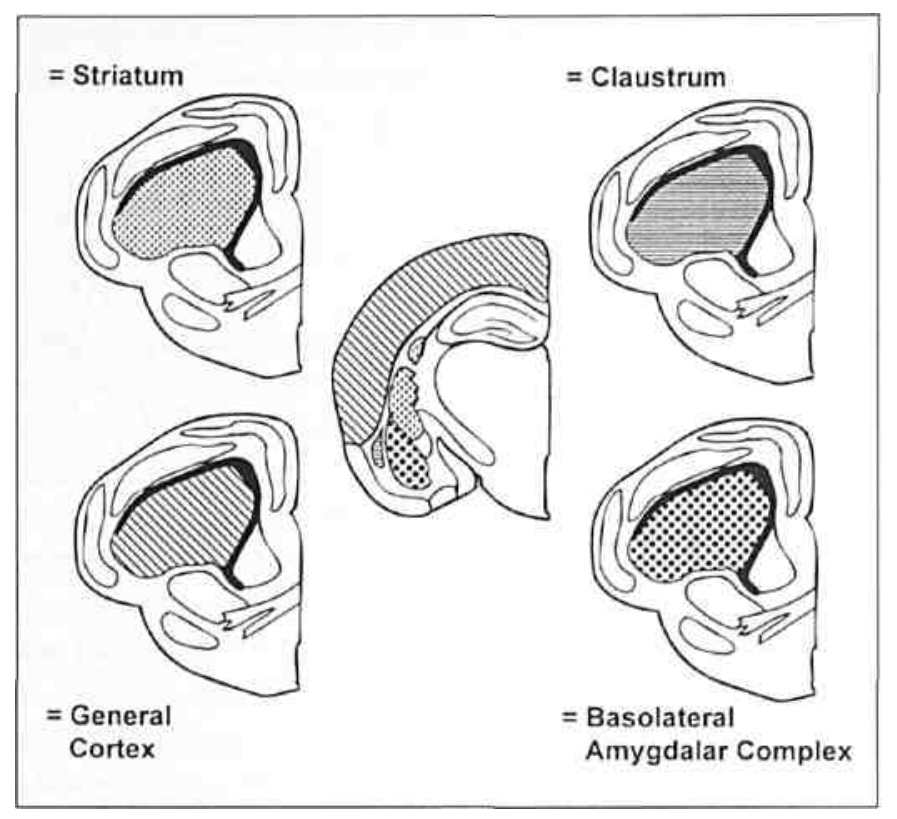

Fig. 1. Suggested homologies between reptilian DVR and various mammalian regions shown in four outline drawings of a section through the mid-telencephalon of Gekko surrounding a drawing of a section through the mid-telencephalon of a rat. Upper left, DVR homologous to the striatum (diamonds) [Elliot Smith, 1919; Dart, 1920; Ariens Kappers et al., 1936; Hewitt, I967|. Lower left, DVR homologous to portions of general cortex (diagonal lines) [e.g., Karten, 1969, 1991;Northcutt, 1969, 1981; Bruce and Butler, 1984a; Butler, 1994a]. Upper right, DVR homologous to die claustrum (bricks) [Filimonoff, 1964; MacLean, 1990; Diaz, 1990]. Lowerright, DVR compared to the basolateral amygdalar complex (dots) [present paper].

Johnston, 1923; Ariens Kappers etal., 1936; Hewitt, 1967], but following several studies showing its receipt of ascending visual and auditory pathways from the thalamus, it was compared to portions of isocortex (fig. 1) [e.g., Karten, 1969, 1991; Northcutt, 1969, 1981; Bruce and Butler, 1984a; Butler, 1994a].

This is the currently prevailing viewpoint, but it is not without challenge. Lohman and Smeets [1991] and Smeets and Gonzalez [1994] have recently argued against a homology between the rDVR and isocortex, whereas Diaz et al. [1990], primarily on the basis of cell morphology, considered the rDVR to be related to the claustrum (fig. 1). In this paper, which is a continuation of our ongoing analysis of limbic system evolution [e.g., Bruce and Neary, 1995a, b; Neary, 1995], we shall also question the homology between the rDVR and isocortex and, instead, propose that the rDVR is related to the basolateral amygdalar complex of mammals. Furthermore, we shall also consider recent

\section{5}

evidence suggesting that the traditional homologies between pallia! fields of various amniotes may not be entirely correct.

\section{Cortical Comparisons}

The pallium of amphibians has long been parceled into three principal divisions, now generally referred to as the lateral, dorsal, and medial pallial fields [RSthig, 1912; Aliens Kappers et al., 1936; Herrick, 1948; Northcutt, 1981]. These divisions have generally been compared to the lateral, dorsal, and medial cortices of reptiles and these cortices, in turn, to the piriform, general (i.e., non-olfactory, 
non-hippocampal), and hippocampal cortices of mammals (fig. 2). These is little controversy regarding the first of these comparisons; the lateral pallium, lateral cortex, and piriform cortex are the primary targets of the main olfactory bulb, reciprocate thfs connection, and occupy similar positions in the hemisphere [e.g., Northcutt and Royce, 1975; Scalia and Winans, 1975; Scalia, 1975; Halpern, 1980; Northcutt, 1981; Neary, 1990; Martinez-Garcia et al., 1991; Scalia et al., 1991]. The validity of the comparison of the dorsal pallium with dorsal cortex and general cortex, however, is less certain. It is true that all three areas receive a substantial ascending input from the rostral thalamus, have projections to the olfactory bulb, and occupy a similar position in the hemisphere [Bruce and Butler, 1984a; Neary, 1984, 1990; Desan, 1988; Hoogland and Vermeulen-VanderZee, 1989]. Nevertheless, in contrast to the dorsal and general cortices, the dorsal pallium receives a substantial input from the main olfactory bulb, lacks commissural connections, and does not appear to project outside the hemisphere [Northcutt and Royce, 1975; Scalia, 1976; Neary, 1990; Scalia et al., 1991]. For these reasons, it is doubtful that the dorsal pallium is homologous to the dorsal and general cortices, and it is more likely to be homologous to a portion or portions of the olfactory cortex in reptiles and mammals (fig. 2).

The medial pallium of amphibians has traditionally been compared to the medial cortex of reptiles and the hippocampal cortices of mammals, and they do have many similar connections [Bruce and Neary, 1995b]. However, the medial pallium also has many connections in common with the dorsal cortex. These include projections to the olfactory bulb, hypothalamus, thalamus, and midbrain, projections to the contralateral side, and a relative absence of direct olfactory input [Br uce and Butler, 1984a; Hoogland and Vermeulen-VanderZee, 1989; Neary, 1990; Northcutt and Ronan, 1992], Thus, the medial pallium may also be

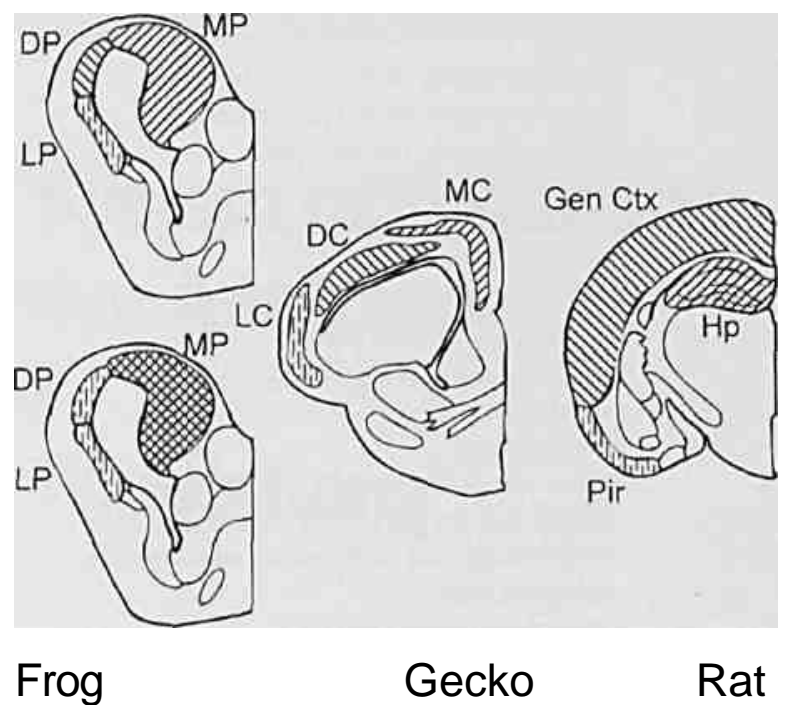

Fig. 2. Summaries of various cortical comparisons in amphibians (left), reptiles (center), and mammals (right) shown in outline drawings of sections through the mid-telencephalon. Traditional pallial comparisons between amphibians (upper left) and amniotes (middle, right) proposed three homologous fields: olfactory (vertical hash marks), general (backslashes), and hippocampal (forward slashes). The current proposal suggests that the dorsal and lateral pallia of amphibians are comparable to olfactory cortices of reptiles and mammals (lower left, middle, right) and that the medial pallium of amphibians is comparable to both the dorsal and medial cortices of reptiles and the general and hippocampal cortices of mammals.

homologous to both the medial and dorsal cortices in reptiles.

There is general agreement that the medial cortex of reptiles is homologous to part of the hippocampus of mammals and that the lateral cortex is homologous to the piriform cortex [e.g., Aliens Kappers et al., 1936; Northcutt, 1969; Butler, 1994a]. However, with regard to the dorsal cortex, disagreement is 
rampant, and numerous mammalian homo-logues for this area have been proposed (singly or in combinations): Amnion's horn, ventral subicular cortex, isocortex (in part or in whole), medial entorhinal cortex, in-fralimbic cortex, and agranular insular cortex [Aliens Kappers et al., 1936; Northcutt, 1969, 1981; Hall and Ebner, 1970; Desan, 1988; Hoogland and Vermeulen-VanderZee, 1989; Reiner 1991, 1993; Butler, 1994a; Bruce and Neary, 1995b]. With the exception of Ammon's horn, all of the structures in the list are included in what we term 'general* cortex (non-hippocampal and non-olfactory cortices) and have several elements in common with dorsal cortex:

226

BuceNeary

TetrapodLimbic System

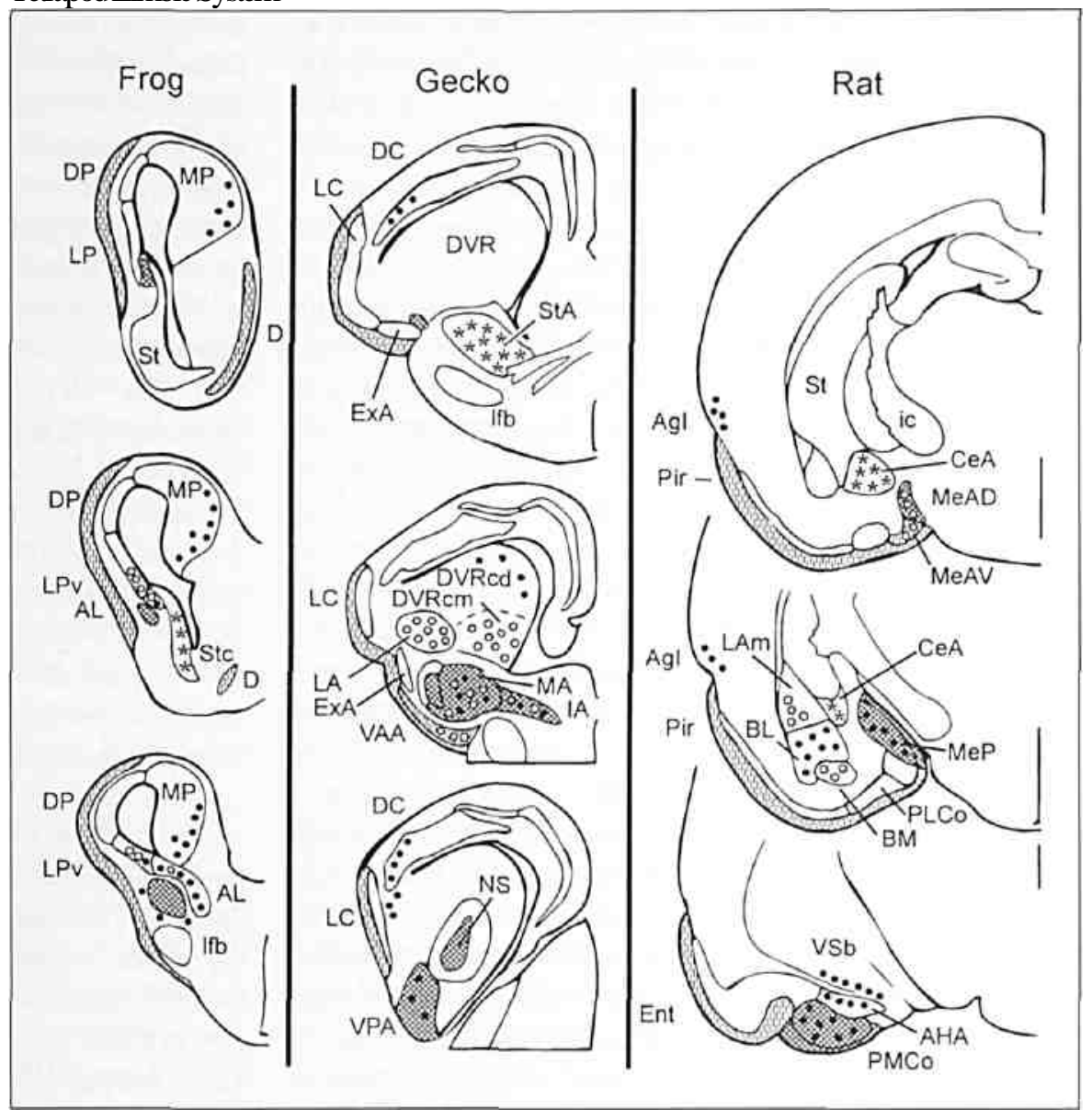

Fig. 3. Summary of olfactory and vomeronasal targets and the origins of projections to the hypothalamus in amphibians (left). reptiles (center), and mammals (right). Key: Asterisks, cells that have long descending projections to the lateral hypothalamus and brainstem; closed circles, cells that project to the lateral hypothalamic area; open circles, cells that project to the ventromedial hypothalamus (or medial hypothalamus in amphibians); cross-hatching, accessory 
olfactory bulb targets; vertical dashes, olfactory bulb targets. The filled circles in LPv (frog) and the open circle in AL (frog) reflect the uncertainty regarding the type of shift (gradual vs. abrupt?) in going from $\mathrm{LPv}$ to $\mathrm{AL}$ and from neurons that project to the medial hypothalamus vs. neurons that project to the lateral hypothalamus [unpublished observations].

(1)descending projections to the diencephalon and midbrain,

(2)commissural connections, (3) ascending projections from the rostral thalamus ${ }^{1}$, and (4) several histochemically similar cell types [Hall and Ebner, 1970; Hall et al., 1977; Bruce and Butler, 1984a; Desan, 1988; Hoogland and Vermeulen-VanderZee, 1989; Ulinski, 1990; Reiner, 1991, 1993; Bruce and Neary, 1995a]. The major difference between reptilian dorsal cortex and mammalian general cortex is that the dorsal cortex lacks the *inside-ouf migration pattern observed in mammalian isocortex [Goffinet et al., 1986].

\section{Amygdalar Comparisons}

Nuclei with Long Descending Connections All tetrapods appear to possess neuronal populations located in the lateral subpallium that have long descending projections to the hypothalamus and brainstem (fig. 3). In amphibians, these cells are located in the caudal striatum and they project to the hypothalamus, dorsal isthmus, and caudal medulla [ten Donkelaar et al., 1981; Toth et al., 1985; Wetzel et al., 1985; Allison and Wilczynski, 1991; Neary, 1995]. Comparable populations are present in reptiles and birds, located in the striatoamygdalar area of lizards, area d of turtles, and portions of the archistriatum in birds [Zeier and Karten, 1971; Nottebohm et al., 1976; Russchen and Jonker, 1988; Siemen and Kiinzle, 1994].

The amygdalar nuclei can be grouped on the basis on their major connections: those with long descending projections, those receiving olfactory projections, those lacking olfactory projections but projecting to the hypothalamus, and those receiving ascending input from the caudal dorsal thalamus.

\footnotetext{
${ }^{1}$ The cortical homologies we propose in this paper imply homologies among the thalamic groups associated with them. Specifically, the anterior thalamic nucleus in amphibians and the dorsomedial and dorsolateral anterior nuclear complex in reptiles [Neary, 1990; Butler, 1994a] would be homologous, as a group, with die medial, anterior, ventral, lateral, and metathalamic nuclear groups that project to the cortical mantle in mammals.
}

\section{7}

These populations are most likely homologous to the central amygdalar nucleus and portions of the extended amygdala in mammals [Ulinski, 1983; Russchen and Jonker, 1988; Siemen and KUnzle, 1994; Alheid and Heimer, 1988; Bruce and Neary, 1995b].

\section{Nuclei with Olfactory Connections}

In amphibians, reptiles, and mammals the main olfactory bulb projects to the surface of a number of cortical structures along the lateral wall of the telencephalon (fig. 3). In amphibians, these structures include the lateral and dorsal pallia [Northcutt and Royce, 1975; Neary, 1990; Scalia et al., 1991]. In reptiles, the lateral cortex, external amygdala, and ventral anterior amygdala receive an olfactory projection [Lohman et al, 1988; Martinez-Garcia et al., 1991]. In mammals, the olfactory (or piriform) cortex, the entorhinal cortex, posterolateral cortical amygdala, and the anteroventral division of the medial amygdala receive an olfactory projection [Scalia and Winans, 1975; deOlmos et al., 1978]. Based on their olfactory connections, these areas in amphibians, reptiles, and mammals appear to be homologous. These olfactory recipient cortical groups can be further subdivided on the basis of a projection to the hypothalamus, specifically to the core of the ventromedial hypothalamic nucleus (VMH). In amphibians, the caudal pole of the ventral division of the lateral pallium projects heavily to 
the hypothalamus [Neary, 1995]; in reptiles the ventral anterior amygdala receives an olfactory projection and projects to the VMH [Lohman et al., 1988; Martinez-Garcia et al., 1991; Bruce and Neary, 1995a], and in mammals only the anteroventral division of the medial amygdala has comparable connections [deOlmos et al., 1985]. These nuclei have comparable topological positions (fig. 3).

The lateral amygdala of amphibians receives a projection from the accessory olfactory bulb [Northcutt and Royce, 1975; Scalia. 1972; Scalia et al., 1991] and projects to the hypothalamus [Wilczynski and Allison, 1989; Allison and Wilczynski, 1991; Neary, 1995]. The lateral amygdala in ranid amphibians appears to be homologous to the medial, interstitial, and ventral posterior amygdalar nuclei in lizards. These populations receive accessory olfactory projection's and project to the lateral and medial hypothalamus [Bruce and Neary, 1995a]. Of these, the medial and interstitial amygdalar nuclei project to the VMH core and sparsely to the lateral hypothalamus, whereas the ventral posterior amygdalar nucleus projects to the lateral hypothalamus [Bruce and Neary, 1995a]. An additional target of the accessory olfactory bulb in some reptiles, nucleus sphericus, appears not to have an obvious counterpart in amphibians or mammals, because it is apparently the only

accessory olfactory target that lacks a hypothalamic projection. Whether nucleus sphericus represents an unique elaboration of the medial amygdala or is formed by the invasion of growing axons into a new target area will require further study. In rodents, the anterodorsal division of the medial amygdala, and parts of the bed nucleus of stria terminalis receive an accessory olfactory projection and project to the VMH core, and the posterior division of the medial amygdala and posteromedial cortical amygdala receive an accessory olfactory projection and project to the lateral hypothalamus [Scalia and Winans, 1975; deOlmos et al., 1985; Gomez and Newman, 1992]. Thus (1) the medial and interstitial amygdalar nuclei, and (2) the ventral posterior amygdalar nuclei of lizards appear to be homologous with (1) the anterodorsal division of the medial amygdala and parts of the bed nucleus of stria terminalis, and (2) the posterior division of the medial amygdala and posteromedial cortical amygdala of rodents, respectively. They also have a similar topological organization, as demonstrated in figure 3.

\section{Nuclei Projecting to the Hypothalamus}

The caudal LPv of frogs is the only pallial population that receives input from both the main olfactory bulb [Scalia, 1976; Northcutt and Royce, 1975; Scalia et al., 1991] and the hypothalamus [Neary and Wilczynski, 1977]. It also projects to the hypothalamus [Wilczynski and Allison, 1989; Neary, 1995], specifically to the medial hypothalamus via the stria terminalis [unpublished observations]. The caudal LPv may be homologous to at least four populations in the caudal telencephalon of reptiles [Bruce and Neary, 1995a, b]: (1) the ventral anterior amygdala (see above); (2) the centromedial DVR, which receives a hypothalamic projection and projects through the stria terminalis to the VMH; (3) the lateral amygdalar nucleus, which projects to the VMH through the stria terminalis; and (4) the caudal, ventral part of the lateral cortex (an olfactory bulb target), which lies superficial to the caudal DVR and lateral amygdalar nucleus.

The lateral amygdalar nucleus of reptiles is similar to the basomedial amygdala of mammals both connectionally and topologically [Bruce and Neary, 1995a]. Both project to the VMH core and the lateral amygdalar nucleus receives input from the rostral DVR, whereas the basomedial amygdala receives input from the lateral amygdala, a population that we believe comparable to the rostral DVR (see below) [Vo-neida and Sligar, 1979; deOlmos et al, 1985; Bruce and Neary, 1995a]. In terms of topology, the lateral amygdalar nucleus in reptiles and the basomedial amygdala in mammals have similar relations, albeit rotated by $90^{\circ}$, to several comparable structures (fig. 3). The lateral amygdala lies di-

\section{8}

Bruce/Neary

Tetrapod Limbic System

rectly medial to two main olfactory bulb targets, the lateral cortex and the external amygdalar nucleus. The basomedial amygdala lies directly dorsal to two main olfactory bulb targets, the piriform cortex and posterolateral cortical amygdala. In reptiles, the lateral amygdala is surrounded dorsally, medially, and rostrally by the DVR, and ventrally by the medial amygdalar nucleus. In mammals, the basomedial 
amygdala is surrounded laterally, dorsally, and rostrally by the basolateral (and lateral) amygdala, and medially by portions of the medial amygdala.

Portions of the caudodorsal DVR of geckos appear to project to the lateral hypothalamus, and this region has been compared to the basolateral amygdala of mammals, which also projects to the lateral hypothalamus [McBride and Sutin, 1977; Krettek and Price, 1978; Bruce and Neary, 1995b]. In terms of topological relationships, the caudodorsal DVR is adjacent to the lateral amygdalar nucleus and centromedial DVR. Similarly, in rats the basolateral amygdala is adjacent to the basomedial amygdala (see above for comparison) and the ventrolateral part of the lateral amygdala (see below for comparison).

Finally, the centromedial DVR projects through the stria terminalis to the core of VMH [Bruce and Neary, 1995a]. The only VMH-projecting region in mammals with comparable topological relationships is the ventrolateral part of the lateral amygdala (LaVL) [deOlmos et al., 1985] (fig 3). Both the DVRcm in reptiles and the LaVL in mammals are contiguous with a region (rDVR or Lam) receiving massive sensory inputs from the caudal thalamus, with a subolfacto-ry region projecting to the VMH core (LA or BM), with an area projecting to the lateral hypothalamus (DVRcd or BL), and with an area projecting to the brainstem (StA or CeA). However, this line of reasoning implies that the DVR is comparable to the basolateral amygdalar complex and, more specifically, that the rDVR and the DVRcm together are comparable to the lateral amygdala. The validity of this suggestion will be dealt with in the next section.

\section{Nuclei Receiving Ascending Input from the Caudal Dorsal Thalamus}

In all tetrapods, populations in the lateral part of the telencephalic hemisphere receive ascending input from the caudal thalamus. These populations are located in the dorsal and ventral striatum and LPv of amphibians, in the striatum and rDVR of reptiles, and in the striatum, basolateral amygdalar complex, claustrum, and general cortex of mammals.

The striatum of amphibians has generally been compared to the striatum of reptiles [Northcutt, 1969, 1981; Parent, 1986], but the dorsal striatum has also been com-

pared to the rDVR [RSthig, 1912; Herrick, 1948], as has the striatum as a whole [Braford, 1994]. Other structures that have been compared to the rDVR include the dorsal pallium [Butler, 1994a] and portions of the lateral pallium [Northcutt, 1974; Northcutt and Kicliter, 1980; Neary, 1990]. All of these areas are similar to the rDVR in receiving ascending thalamic projections. However, the dorsal pallium possesses several connections not ascribed to the rDVR, including reciprocal connections with the olfactory bulb and septal area, and it appears to lack a projection to the striatum [Neary, 1990]. No detailed studies of the lateral pallial or dorsal vs. ventral striatal connections have been performed. These would appear to be necessary in evaluating the relative merits of proposed homologies between these structures and the rDVR.

Evidence taken from connectional and histochemical studies strongly supports the homology between striatum in reptiles and that in mammals [Reiner et al., 1984]. The older idea that the rDVR of reptiles was related to the striatum of mammals was based primarily on topology and has been largely discounted on the basis of embryological, connectional, and histochemical studies [e.g., Kallen, 1951; Karten, 1969; Northcutt, 1978]. Current candidates for a mammalian homologue include the isocortex, claustrum, and the basolateral amygdalar complex.

The similarities between the rDVR and parts of the isocortex have been discussed extensively [e.g., Ulinski, 1984; Butler, 1994a; Reiner, 1993]. To summarize briefly, both are derived embryologically from the pallium, both receive ascending sensory thalamic projections, and both project to striatum. This comparison suggests that the principal sensory thalamic areas of mammals and reptiles are homologous [e.g., Butler, 1994b]. On the other hand, isocortex has a number of connections that the rDVR lacks, including interhemispheric connections and long descending connections to the thalamus and brainstem (fig.4). Finally, the isocortex has an *inside-ouf pattern of histogenesis [e.g., Bayer and Airman, 1991a], whereas the DVR has an *outside-in' pattern [Tsai et al., 1981a, b].

Several investigators have compared the rDVR to the claustrum of mammals [Filimonoff, 1964; MacLean, 1990; Diaz et al., 1990]. Connections that the claustrum and rDVR have in common include reciprocal connections with the ipsilateral cortex, a thalamic afferent projection, and a 
projection from locus coeruleus. Both lack projections to the thalamus and brainstem [LeVay and Sherk, 1981]. Thalamic projections to the claustrum do not arise from the main sensory nuclei of the thalamus but, rather, from an intralaminar population, nucleus centralis [LeVay and Sherk, 1981], thus suggesting that the thalamic nuclei pro-

Fig. 4. Comparison of the connections of the rostral DVR in mammals with those of the isocortex, claustrum, and lateral amygdala in mammals. Note that the smallest number of changes in connections from a common ancestral condition would be required if the rostral and centromedial portions of the DVR are homologous to mammalian lateral amygdala. A homology with the general cortex or claustrum would require significant gains and losses of connections.

| |psi Ctx | 
$\wedge \quad$ *.

Striatum StA

$>$ L/J DVR

$x i \sim$

ig"

* $\mathrm{KS}$

VMH I

| Ipsi Ctx | Contra Ctx 


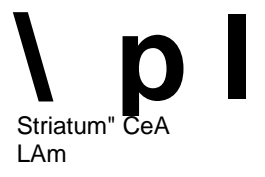

Sup Cotl Spinal Cord

InfColl

${ }^{\star}>$ S. $^{\wedge * \star \wedge}$

sl

Sup Coll Inf Coll RedN Pontine N Spinal Cord 
| Ipsi Ctx | | Contra Ctx

11

Sup Coll Spinal Cord N Cuneiformis

IT-, I 1

$\wedge_{\Perp}$

f

| Ipsi Ctx | 
CeA

Sup Coll Spinal Cord

InfColl

$>f 7 / / 7>$

for $\wedge$

----- b- $f A \quad 1 \mathrm{Am}$

gg

$\wedge U Z / J U-$ 
jection to the rDVR in reptiles are related to intralaminar nuclei of mammals. However, the connections of the rDVR and claustrum also differ in several aspects (fig. 4). The claustrum is reciprocally connected with the contralateral isocortex and receives a projection from the lateral hypothalamus [LeVay and Sherk 1981]. The rDVR appears to lack these connections. Conversely, the rDVR projects to the striatum and receives a dopaminergic projection from the midbrain tegmentum [Northcutt, 1970; Hoogland, 1977; Ulinski, 1978; Smeets et al., 1986], and the claustrum appears to lack these connections. Thus, with respect to connectivity, there are about as many differences between the claustrum and rDVR as there are between isocortex and rDVR. Finally, the claustrum and rDVR appear to have differing patterns of development, with the claustrum arising from and migrating out of the neocortical neu-roepithelium and the rDVR forming in situ [Ulinski, 1983; Bayer and Airman, 1991b]. A comparison of the connections, topological relations, and embryology of the rDVR and the lateral amygdala (of the basolateral complex) in mammals reveals a remarkable number of similarities, suggesting that these two areas are related (fig. 4): (1) the receipt of ascending sensory thalamic projections $^{2}$; (2) projections to striatum; (3) absence of long descending connections to the thalamus and brainstem (possessed by isocortex); (4) absence of interhemispheric

The proposed homology between the rDVR in reptiles and lateral amygdala in mammals implies that the sensory thalamic areas projecting to these regions are also homologous as a group.Thus medialis (reunions), medialis posterior, posteroventralis. postero-centralis, and rotundus in reptiles would be comparable to posterior and intralaminar thalamic groups, including the medial division of the medial geniculate, supragcniculate, posterior intralaminar nucleus, lateral subparafascicular thalamic nucleus, and peripedun-cular region in mammals [e.g., Ulinski, 1983; Bruce and Butler, 1984b; LeDoux et al., 1985, 1990; Turner and Herkcnham. 1991; Pritz, 1995). Interestingly, most of these thalamic groups appear to receive a bilateral brainstem or spinal cord projection that reaches its contralateral target by crossing through the supraoptic decussation leg.. Braford, 1972; Pritz, 1974; Holstege and Collewijn, 1982; Pritz and Stritzcl. 1990; Giesler et al., 1994; W.B. Warr, personal communication),

230

Brucc/Neary

Tetrapod Limbic System 

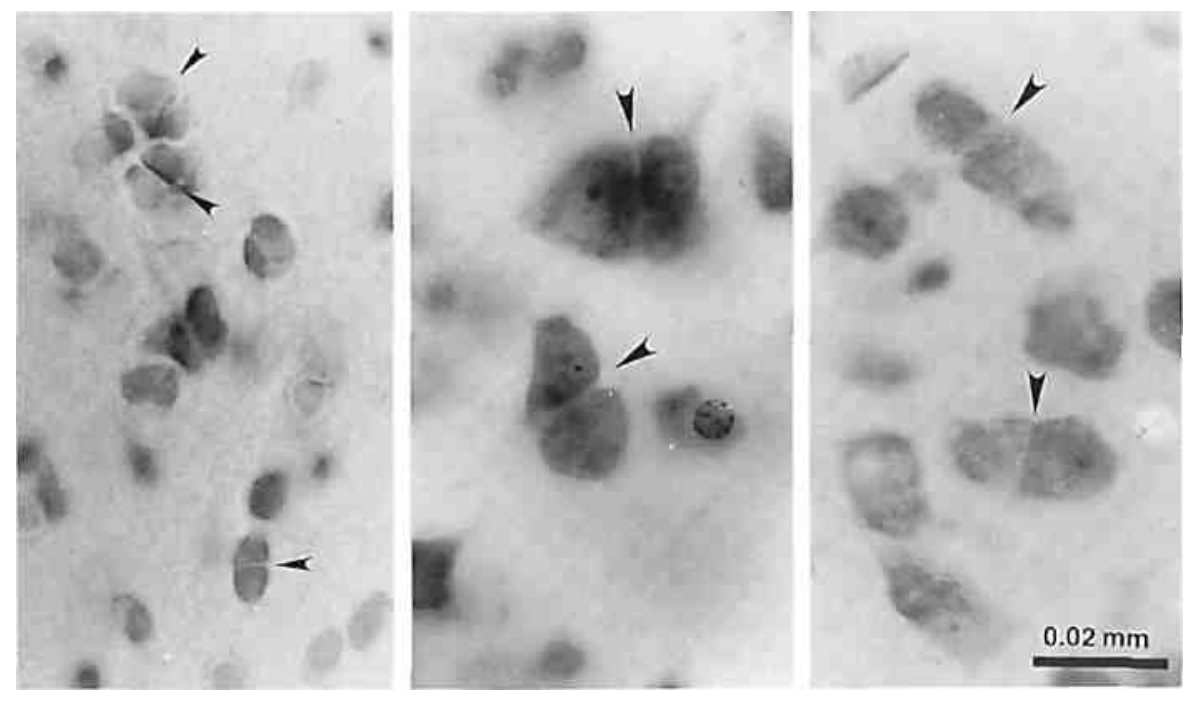

Fig. 5. Comparison of cell morphology in the rostral DVR of a gecko (left), the lateral amygdala of an opossum (center), and the lateral amygdala of a rat (right). Note that in all cases there are frequently tight clusters of two or more cells with closely opposed soma! membranes (arrows).

connections (possessed by isocortex); (5) comparable positions deep to the olfactory cortex; (6) position along the ventricular surface; and (7) a neurogenetic gradient that proceeds from outside to in [Krettek and Price, 1978; Bayer, 1980; Kelley et al., 1982; Paxinos and Watson, 1982; Ulinski, 1983; Russchen and Price, 1984; LeDoux et al., 1985, 1990; Turner and Herkenham, 1991; Butler, 1994a; Pritz, 1995].

In addition, the morphology of DVR neurons in reptiles is similar to that of basolateral amygdalar neurons in mammals. In reptiles, up to five cell types can be recognized [Northcutt, 1970; Balaban, 1978; Ulinski, 1978; Clark and Ulinski, 1984; Diaz et al., 1990], and four of these types have been described in mammals [McDonald, 1982]. Two types of multipolar cells, multipolar polygonal and multipolar pyramidal neurons, are present in reptiles, and their morphology is very similar to that of the class II multipolar cells and class I pyramidal/piriform cells found in rats. In both reptilian DVR and mammalian amygdala, pyramidal neurons lack a preferred orientation, thus differing from cortical pyramidal neurons, which are oriented perpendicular to the surface [Hall, 1972; Kamal and Tombol, 1975; McDonald, 1982]. The bitufted subtype I cell of lizards [Diaz et al., 1990] is morphologically similar to the class II bipolar cell of mammals [McDonald, 1982]. Both extend a single dendrite from each pole. The last category is a mul-tidendritic bitufted neuron, characterized by its fusiform shape and multiple dendrites exiting from its poles. These are represented by the bitufted subtype II and in cells of lizards [Diaz et al., 1990] and the class $\mathbf{n}$ bitufted and chandelier cells of mammals [McDonald, 1982]. It should be

noted, however, that not all DVR and amygdalar neurons have counterparts. The juxtaependymal cell, present in lizards [Diaz et al., 1990], has not been described in mammals, and class HI neurons (neurogliaform cells) of mammals [McDonald, 1982] have not been described in reptiles. Nonetheless, the most commonly observed cell types appear to be present in both mammals and reptiles. 
One cytoarchitectonic feature of the DVR not found in dorsal cortex or other reptilian telencephalic regions is the presence of tight clusters of cells with soma-somal junctions [Ulinski, 1976; Diaz et al., 1990], These junctions resemble electrical synapses and may allow synchronous activation of neurons in a particular cell cluster [Ulinski, 1976], Such contacts have not been described in mammalian isocortex [Ulinski, 1983], but cell clusters are frequent in mammalian basolateral amygdalar complex [Koikegami, 1963] (fig. 5).

\section{Conclusions}

The continuous advancement in our knowledge of connections within the brains of vertebrates makes it possible to repeatedly test and adapt our ideas regarding brain evolution. Recent studies of the limbic system of tetrapods have made data available that challenge some of the long-held tenets of forebrain evolution. In the past 25 years, the most widely accepted explanation of the data on forebrain sensory pathways available has been that essentially first proposed by Karten [1969]. Using the basic principle of parsimony — that best hypotheses concerning homologies

231

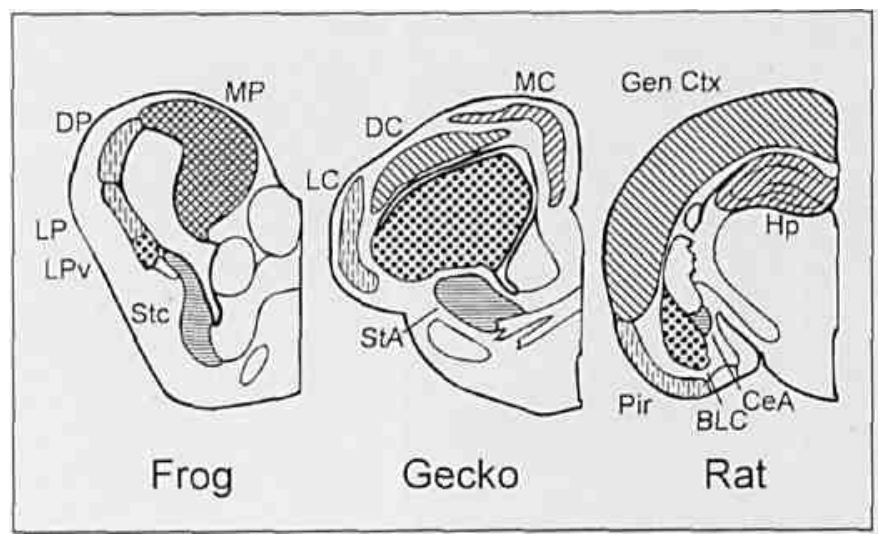

Fig. 6. Summary of several proposed homologies between telen-cephalic areas of amphibians (left), reptiles (center), and mammals (right). Amphibian medial pallium (cross hatching) is considered comparable to reptilian dorsal (backslashing) and medial (forward slashing) cortices and mammalian general (backslashing) and hippo-campal (forward slashing) cortices. Main olfactory bulb targets (vertical hash marks) are considered homologues. The caudal part of LPv (dots) is homologous to part of the DVR, and the DVR is considered comparable to the basolateral amygdalar complex of mammals. Finally, the caudal striatum of amphibians (horizontal lines) is homologous to the stri atoamygdal ar area of reptiles and the central amygdalar nucleus of mammals. See text for additional proposals.

(4) The cortical targets of the main olfactory bulb in amphibians (lateral and dorsal pallia), reptiles (external amygdala and lateral cortex), and mammals (piriform cortex, entorhirial cortex, anteroventral division of the medial amygdala, and posterior lateral cortical amygdala) appear to be homologous, and the common ancestor probably had a corresponding olfactory pallial field.

(5) The targets of the accessory olfactory bulb in amphibians (lateral amygdala), reptiles (medial amygdala, ventral posterior amygdala, and nucleus sphericus), and mammals (medial posterior amygdala) appear to be homologous, with the exception of nucleus sphericus which lacks an obvious non-reptilian homologue.

\section{Acknowledgments}


The authors would like to dedicate this paper to the memory of WJ.H. Nauta for inspiring us to investigate the evolution of the limbic system. We are especially grateful to Mark Braford for inviting us to the Karger Workshop and to Thomas Karger for his gracious generosity.

are those that require the fewest number of evolutionary changes - we have reevaluated comparisons in the tetrapod limbic system and have reached different conclusions. Given the current data, the following points appear to be justified (fig. 6):

(1) The common ancestors of reptiles and mammals hada well-developed limbic system in which the basic subdivisions and connections of the amygdalar nuclei wereestablished.

(2)Greater changes occurred in the amygdala in the amphibian-reptilian transition than in the reptilian-mammalian transition. The amphibian caudal LPv appears to be a single structure which corresponds to at least four areas in reptiles: centromedial DVR, ventral anterior amygdala, lateral amygdala, and part of the lateral cortex.

(3)The medial pallium in amphibians appears to be homologous to the dorsal and medial cortices in reptiles and to the general and hippocampal cortices in mammals. Amphibian and reptilian homologues, although segregated differently, appear to be largely associated with limbic functions. Mammalian homologues are similar topological-ly to their counterparts in reptiles but have dramatically increased in size and have developed large areas for non-limbic sensory and motor processing.

232

Bruce/Neary

Tetrapod Limbic System

References

Alheid, G.F., and L. Heimer (1988) New perspectives in basal forebrain organization of special relevance for neuropsychiairic disorders: the striatopallidal, amygdaloid, and corticopetal components of substantia innominata. Ncuro-science, 27:1-39.

Allison, J.D., and W. Wilczynski (1991) Thalamic and midbrain auditory projections to the preoptic area and ventral hypothalamus in the green treefrog (Hyla cinerea). Brain Behav. Evol., 38:322-331.

AriSns Kappers, C.U., G.C. Huber, and E.C. Crosby (1936) The Comparative Anatomy of the Nervous System of Vertebrates, Including Man. Reprinted 1960. Hafner, New York.

Balaban, CD. (1978) Structure of anterior dorsal ventricular ridge in turtles (Pseudemys scripta elegans). J. MorphoL, 158:291-322.

Bayer, S.A. (1980) Quantitative ${ }^{3} \mathrm{H}$-thymidine radiographic analyses of neurogenesis in the rat amygdala. J. Comp. Neurol., 194:845875.

Bayer, S.A., and J. Allman (1991a) Neocortical Development. Raven, New York.

Bayer, S.A., and J. Altman (1991b) Development of the endopiriform nucleus and the claustrum in the rat brain. Neuroscience, 45:391 — 412.

Braford, M.R., Jr. (1972) Ascending efferent tectal projections in the South American spectacled caiman. Anat. Rec, 172:275-276.

Braford, M.R., Jr. (1994) Are the amphibian 'striatum' and the reptilian anterior dorsal ventricular ridge homologous? Soc. Neurosci.

Abstr.,20;997

Bruce, L.L., and A.B. Butler (1984a) Telence-phalic connections in lizards. I. Projections to cortex. J. Comp. Neurol., 229:585-601.

Bruce, L.L., and A.B. Butler (1984b) Telence-phalic connections in lizards. IX Projections to anterior dorsal ventricular ridge. J. Comp.

Neurol., 229:602-615.

Bruce, L.L., and T.J. Neary (1995a) Afferent projections to the ventromedial hypothalamus in a lizard, Gekko gecko. Brain Behav. Evol., 46: 14-29.

Bruce, L.L., and T.J. Neary (1995b) Afferent projections to the lateral and dorsomedial hypothalamus in a lizard, Gekko gecko. Brain Behav. Evol., 46:30-42.

Butler, A.B. (1994a) The evolution of the dorsal pallium in the telencephalon of amniotes: cla-distic analysis and a new hypothesis. Brain Res. Rev., 19:66-101.

Butler, A.B. (1994b) The evolution of the dorsal thalamus of jawed vertebrates, including mammals: cladistic analysis and a new hypothesis. Brain Res. Rev., 19:29-65.

Clark, J.M., and RS. Ulinski (1984) A Golgi study of the anterior dorsal ventricular ridge in the alligator Alligator mississippiensis. J. MorphoL, 179:153-174.

Dart, R.A. (1920) A contribution to the morphology of the corpus striatum. J. Anat., Lond., 55: 1-35.

deOlmos, J.S., G.E Alheid, and C.A. Beltramino (1985) Amygdala. In The Rat Nervous System, Vol. 1, Forebrain and Midbrain (ed. by G. Paxi-nos). Academic Press, Orlando, pp. 223-334.

deOlmos, J., H. Hardy, and L. Heimer (1978) The afferent connections of the main and the accessory olfactory bulb formations in the rat: An experimental HRP-study. J. Comp. Neurol., 181:213-244. 
Desan, P.H. (1988) Organization of the cerebral cortex in turtle. In The Forebrain of Reptiles (ed. by W.K. Schwerdlfeger and W.J.A.J. Smeets), Karger, Basel, pp. 1-11.

Diaz, C, C. Yanes, L. Medina, M. Monzon, CM. Trujillo, and L. Puelles (1990) Golgi study of the anterior dorsal ventricular ridge in a lizard. 1. Neuronal typology in the adult. J. Morphol., 203:293-300.

Elliot Smith, G. (1919) A preliminary note on the morphology of the corpus striatum and the origin of the neopallium. J. Anat., Lond., 53: 271-291.

Filimonoff, LN. (1964) Homologies of the cerebral formations of mammals and reptiles. J. Himforsch., 7:229-251.

Giesler, G.J., Jr, J.T. Katter, and R.J. Dado (1994) Direct spinal pathways to the limbic system for nociceptive information. Trends Neurosci., 17: 244-250.

Goffinet, A.M., C. Daumerie, B. Langerwerf, and C. Pieau (1986) Neurogenesis in reptilian cortical structures: ${ }^{J} \mathrm{H}-\mathrm{thymidine}$ autoradiographic analysis. J. Comp. Neurol., 243:106-116.

Gomez, DM., and S.W. Newman (1992) Differential projections of the anterior and posterior regions of the medial amygdaloid nucleus in the Syrian hamster. J. Comp. Neurol., 317: 195-218.

Hall, E. (1972) Some aspects of the structural organization of the amygdala. In The Neurobiology of the Amygdala (ed. by B.E. Eleftheriou), Plenum, New York, pp. 95-121.

Hall, J.A., R.E. Foster, F.F. Ebner, and W.C Hall (1977) Visual cortex in a reptile, the turtle (Pseudemys scripta and Chrysemys picta). Brain Res., 130:197-216.

Hall, W.C, and F.F. Ebner (1970) Parallels in the visual afferent projections of the thalamus in the hedgehog (Paraechinus hypomelas) and the turtle (Pseudemys scripta). Brain Behav. Evol., J: 135-154.

Halpem, M. (1980) The telencephalon of snakes. In Comparative Neurology of the Telencephalon (ed. by S.O.E. Ebbesson), Plenum, New York, pp. 257-295.

Herrick, C.J. (1948) The Brain of the Tiger Salamander. Univ. of Chicago, Chicago.

Hewitt, W. (1967) The basal ganglia of Testudo graeca. J. Comp. Neurol., 131:605-614.

Holstege, G., and H. Collewijn (1982) The efferent connections of the nucleus of the optic tract and the superior colliculus in the rabbit $\mathrm{J}$. Comp. Neurol., 209:139-175.

Hoogland, P.V. (1977) Efferent connections of the striatum in Tupinambis nigropunctattts. J. Morphol. 152:229-246.

Hoogland, P., and E. Vermeulen- VanderZee (1989) Efferent connections of the dorsal cortex of the lizard Gekko gecko studied with Phaseolus vulgaris leucoagglutinin. J. Comp. Neurol., 255:289-303.

Johnston, J.B. (1923) Further contributions to the study of the evolution of the forebrain. J. Comp. Neurol., 35:337-481.

Kallen. B. (1951) On the ontogeny of the reptilian forebrain. Nuclear structures and ventricular sulci. J. Comp. Neurol.. 95:304-347.

Kamal, A.M.. and T TombSI (1975) Golgi studies on the amygdaloid nuclei of the cat. J. Himforsch., 16: $175-201$.

Karien. H.J. (1969) The organization of the avian telencepahalon and some speculations on the phylogeny of the amruote telencephalon.

Ann. N.Y. Acad. Sci., 167:164-179.

Karien. H.J. (1991) Homology and evolutionary origins of the 'neocortex*. Brain Behav. Evol., 38:264-272.

Kelley, A.R., V.H. Domesick, and WJ.H. Nauta (1982) The amygdalostriatal projection in the rat, an anatomical study by anterograde and retrograde tracing methods. Neuroscience, 7: 615-630.

Koikegami, H. (1963) Amygdala and other related limbic structures; experimental studies on the anatomy and function: I. Anatomical researches with some neurophysiological observations. Acta Med. Biol. (Niigata), 10: 161-277.

Krettek, J.E., and J.L. Price (1978) Amygdaloid projections to subcortical structures within the basal forebrain and brainstem in the rat and cat. J. Comp. Neurol., 178:225-254.

LeDoux, J.E., D.A. Ruggiero, and D.J. Rets (1985) Projections to the subcortical forebrain from anatomically defined regions of the medial geniculate body in the rat. J. Comp. Neurol., 242:182-213.

LeDoux, J.E., C. Farb, and D.A. Ruggiero (1990) Topographic organization of neurons in the acoustic thalamus that project to the amygdala. J. Neurosci.. 10:1043-1054.

LeVay, S., and H. Sherk (1981) The visual claustrum of the cat. 1. Structure and connections. J. Neurosci., 1:956-980.

Lohman, A.H.M.. P.V. Hoogland, and RJ.G.M. Witjcs (1988) Projections from the main and accessory olfactory bulbs to the amygdaloid complex in the lizard Gekko gecko. In The Forebrain of Reptiles (ed. by W.K. Schwerdt-feger and W.J.A.J. Smeets), Karger, Basel, pp. 41-49.

Lohman, A.H.M., and W.J.A.J. Smeets (1991) The dorsal ventricular ridge and cortex of reptiles in historical and phylogenetic perspective.

In The Neocortex: Ontogeny and Phylogeny (ed. by B.L. Finlay, G. Innocenti, and H. Scheich), Plenum, New York, pp. 59-74.

MacLean. P.D. (1990) The Triune Brain in Evolution. Plenum, New York.

Martinez-Garcia, E, RE. Olucha, V. Teruel, MJ. Lorentc, and W.K. Schwerdtfeger (1991) Afferent and efferent connections of the olfactory bulbs in the lizard Podarcis hispanica. J. Comp. Neurol., 305:337-347.

McBride, R.L., and J. Sutin (1977) Amygdaloid and pontine projections to the ventromedial nucleus of the hypothalamus. J. Comp. Neurol., 174:377-396.

McDonald, A J. (1982) Neurons of the lateral and basolateral amygdaloid nuclei: A Golgi study in the rat. J. Comp. Neurol., 212:293312.

Nauta, W.J.H., and HJ. Karten (1970) A general profile of the vertebrate brain, with sidelights on the ancestry of cerebral cortex. In The Neu-rosciences Second Study Program (ed. by F.O. Schmitt), Rockefeller University, New York, pp. 7-26.

Neary, TJ. (1984) Anterior thalamic nucleus projections to the dorsal pallium in ranid frogs. Neurosci.Lett.,5/: 213-218.

Neary, T.J. (1990) The pallium of anuran amphibians. In Cerebral Cortex, Vol. 8A, Comparative Structure and Evolution of Cerebral Cortex, Part I (ed. by E.G. Jones, and A. Peters), Plenum, New York, pp. 107-138.

Neary, T.J. (1995) Afferent projections to the hypothalamus in ranid frogs. Brain Behav. Evol., 46:1-13.

Neary, TJ., and W. Wilczynski (1977) Autoradiographic demonstration of hypothalamic effer-ents in the bullfrog, liana catesbeiana. Anat. Rec. 187:665.

Northern i, R.G. (1969) Discussion of the preceding paper. Ann. N.Y. Acad. Sci., 167:180-185.

Northcutt, R.G. (1970) The Telencephalon of the Western Painted Turtle, Chrysemys picta belli. 111. Biol. Monogr., No. 43, University of Illinois, Urbana. 
Northcutt, R.G. (1974) Some histochemical observations on the telencephalon of the bullfrog, liana catesbeiana Shaw. J. Comp. Neurol., 157:379-390.

Northcutt, R.G. (1978) Forebrain and midbrain organization in lizards and its phylogenetic significance. In Behavior and Neurology of Lizards (ed. by N. Greenberg and P.D. Mac-Lean), NIMH, pp. 11-64.

Northcutt, R.G. (1981) Evolution of the telencephalon in nonmammals, Ann. Rev. Neurosci., 4: 301-350.

Northcutt, R.G., and E. Kicliter (1980) Organization of the amphibian telencephalon. In Comparative Neurology of the Telencephalon (ed. by S.O.E. Ebbesson), Plenum, New York, pp. 203-255.

Northcutt, R.G., and M. Ronan (1992) Afferent and efferent connections of the bullfrog medial pallium. Brain Behav. Evol., 40:1-16.

Northcutt. R.G., and GJ. Royce (1975) Olfactory bulb projections in the bullforg Rana catesbeiana. J. Morphol., 145:251-268.

Nottebohm, R, T.M. Stokes, and CM. Leonard (1976) Central control of song in the canary, Serinus carius. J. Comp. Neurol., 165: 457-486.

Parent, A. (1986) Comparative Neurobiology of the Basal Ganglia. Wiley, New York.

Paxinos, G., and C. Watson (1982) The Rat Brain in Stereotaxic Coordinates. Academic Press, Sydney.

Pritz, M.B. (1974) Ascending connections of a midbrain auditory area in a crocodile, Caiman crvcodilus. J. Comp. Neurol., 153:179198.

Pritz, M.B. (1995) The thalamus of reptiles and mammals: similarities and differences. Brain Behav. Evol., 46: 197-208.

Pritz, M.B., and M.E. Stritzel (1990) Thalamic projections from a midbrain somatosensory area in a reptile. Caiman crocodilus. Brain Behav. Evol.. 36; 1-13.

Reiner, A. (1991) A comparison of neurotrans-mitter-specific and neuropeptide-specific neuronal cell types present in turtle cortex to those present in mammalian isocortex: implications for the evolution of isocortex. Brain Behav. Evol.. 38:53-91.

Reiner. A. (1994) Neurotransmitter organization and connections of turtle cortex: implications for the evolution of mammalian isocortex. Comp. Biochem. Physiol., 104A: 735-748.

Reiner. A.. S.E. Brauth. and HJ. Karten (1984) Evolution of the amniote basal ganglia. Trends Neurosci., 7: 320 -325.

Rothig, P. (1912) Bcitragc zum Studium des Cen-tralnervensystems der Wirbelthiere. 5. Die Zellanordnungen im Vorderhlrn der Amphi-bien, mit besonderer Berucksichtigung der Septumkerne und ihr Vergleich mit den Verhaitnissen bei Testudo und Lacerta. Verh. K. Akad. Wet. Amsterdam (Ser. 2), 17:1-73.

Russchen, F.T., and AJ. Jonker (1988) Efferent connections of the striatum and the nucleus accumbens in the lizard Gekko gecko. J. Comp. Neurol., 276:61 -80.

Russchen, F.T., and J.L. Price (1984) Amygdalo-striatal projections in the rat. Topographical organization and fiber morphology shown using the lectin PHA-L as an anterograde tracer. Neurosci. Lett., 47:15-22.

Scalia, F. (1972) The projection of the accessory olfactory bulb in the frog. Brain Res., 36: 409-411.

Scalia, F. (1976) Structure of the olfactory and accessory olfactory systems. In Frog Neurobiology (ed. by R. LlinSs and W. Precht), Springer, Berlin, pp. 213-233.

Scalia, E, and S.S. Winans (1975) The differential projections of the olfactory bulb and accessory olfactory bulb in mammals. J. Comp. Neurol., 163:31-56.

Scalia, F., G. Gallousis, and S. Roca (1991) Differential projections of the main and accessory olfactory bulb in the frog. J. Comp. Neurol., 305:443-461. Siemen, M., and H. KUnzle (1994) Connections of the basal telencephalic areas c and d in the turtle brain. Anat. Embryol., 189:339-359. Smeets, W.J.A.J., and A. Gonzalez (1994) Sensorimotor integration in the brain of reptiles. Eur. J. Morphol.. 32:299-302.

Smeets, WJ.A.J., P.V. Hoogland, and P. Voorn (1986) The distribution of dopamine immuno-reactivity in the forebrain and the midbrain of the lizard Gekko gecko: An immunohisto-chemical study with antibodies against dopamine. J. Comp. Neurol., 253:46-60. ten Donkelaar, HJ., R. de Boer-van Huizen, F.T.M. Schouten, and S J.H. Eggen (1981) Cells of origin of descending pathways to the spinal cord in the clawed toad (Xenopus laevis). Neuro-science, 6:2297-2312. T6th, P.. G. Csank, and G. Lazar (1985) Morphology of cells of origin of descending pathways to the spinal cord in Rana esculenta. A tracing study using cobaltic-lysine complex. J. Hirnforsch., 26; 365-383.

Tsai, H.M., B.B. Garber, and L.M.H. Larramendi (1981a) Thymidine autoradiographic analysis of telencephalic histogenesis in the chick embryo: I. Neuronal birthdates of telencephalic compartments in situ. J. Comp. Neurol., 198: 275-292.

Tsai, H.M., B.B. Garber, and L.M.H. Larramendi (1981b) Thymidine autoradiographic analysis of telencephalic histogenesis in the chick embryo: IL Dynamics of neuronal migration, displacement, and aggregation. J. Comp. Neurol.. 198:293-306.

Turner, B.H., and M. Herkenham (1991) Thala-moamygdaloid projections in the rat: a test of the amygdala's role in sensory processing. J. Comp. Neurol., 313:295-325.

Ulinski, P.S. (1976) Structure of the anterior dorsal ventricular ridge in snakes. J. Morphol., 148: 1-22.

Ulinski.PS. (1978) Organization of anterior dorsal ventricular ridge in snakes. J. Comp. Neurol., 178:411-450.

Ulinski, P.S. (1983) Dorsal Ventricular Ridge: A Treatise on Forebrain Organization in Reptiles and Birds, Wiley, New York.

Ulinski, P.S. (1984) Design features in vertebrate sensory systems. Amer. Zool.,24; 717—731.

Ulinski, P.S. (1990) The cerebral cortex of reptiles. In Cerebral Cortex, Vol. 8A, Comparative Structure and Evolution of Cerebral Cortex, Part I (ed. by E.G. Jones and A. Peters), Plenum, New York, pp. 139-215.

Voneida, T.J.. and CM. Sligar (1979) Efferent projections of the dorsal ventricular ridge and the striatum in the Tegu lizard, Tupinambis nigropunaatus. J. Comp. Neurol., 186:43-64.

Wetzel, D.M., U.L. Haerter, and D.B. Kelley (1985) A proposed pathway for vocalization in South African clawed frogs, Xenopus laevis. J. Comp. Physiol. A, 157:749-761.

Wilczynski, W., and J.D. Allison (1989) Acoustic modulation of neural activity in the hypothalamus of the leopard frog. Brain Behav. Evol., J3.-317-324.

Zeier, H., and H J. Karten (1971) The archistriatum of the pigeon: organization of afferent and efferent connections. Brain Res., 31:313326. 
